Article

\title{
STW 5 Herbal Preparation Modulates Wnt3a and Claudin 1 Gene Expression in Zebrafish IBS-like Model
}

\author{
Monica Piccione ${ }^{1}$, Nicola Facchinello ${ }^{2}$, Sandra Schrenk ${ }^{1}$, Marco Gasparella ${ }^{3}$, Surajit Pathak ${ }^{4}(\mathbb{D}$, \\ Ramy M. Ammar 5,6, Sabine Rabini ${ }^{5}$, Luisa Dalla Valle ${ }^{2,+} \mathbb{D}$ and Rosa Di Liddo ${ }^{1, *,+}(\mathbb{D}$ \\ 1 Department of Pharmaceutical and Pharmacological Sciences, University of Padova, 35131 Padova, Italy; \\ monica.piccione@phd.unipd.it (M.P.); sandra89.schrenk@gmail.com (S.S.) \\ 2 Department of Biology, University of Padova, 35131 Padova, Italy; nicola.facchinello@unipd.it (N.F.); \\ luisa.dallavalle@unipd.it (L.D.V.) \\ 3 Department of Pediatric Surgery, Ca' Foncello Hospital, 31100 Treviso, Italy; marco.gasparella@unipd.it \\ 4 Department of Medical Biotechnology, Faculty of Allied Health Sciences, Chettinad Hospital and Research \\ Institute (CHRI), Chettinad Academy of Research and Education (CARE), Kelambakkam, \\ Chennai 603103, Tamil Nadu, India; surajit.pathak@gmail.com \\ 5 BAYER Consumer Health, Global Medical Affairs, 64295 Darmstadt, Germany; \\ ramy.ammar@bayer.com (R.M.A.); sabine.rabini@bayer.com (S.R.) \\ 6 Department of Pharmacology and Toxicology, Faculty of Pharmacy, Kafrelsheikh University, \\ Kafr-El Sheikh 33516, Egypt \\ * Correspondence: rosa.diliddo@unipd.it; Tel.: +39-0498275636 \\ + The authors contributed equally to the work.
}

\section{check for} updates

Citation: Piccione, M.; Facchinello, N.; Schrenk, S.; Gasparella, M.;

Pathak, S.; Ammar, R.M.; Rabini, S.; Dalla Valle, L.; Di Liddo, R. STW 5 Herbal Preparation Modulates Wnt3a and Claudin 1 Gene Expression in Zebrafish IBS-like Model.

Pharmaceuticals 2021, 14, 1234.

https://doi.org/10.3390/ph14121234

Academic Editors: Óscar López and Carlos Alberto Manssour Fraga

Received: 13 October 2021

Accepted: 24 November 2021

Published: 28 November 2021

Publisher's Note: MDPI stays neutral with regard to jurisdictional claims in published maps and institutional affiliations.

Copyright: (C) 2021 by the authors Licensee MDPI, Basel, Switzerland. This article is an open access article distributed under the terms and conditions of the Creative Commons Attribution (CC BY) license (https:// creativecommons.org/licenses/by/ $4.0 /)$.

\begin{abstract}
Aim: Irritable bowel syndrome (IBS) is a functional bowel disorder characterized by chronic abdominal pain and stool irregularities. STW 5 has proven clinical efficacy in functional gastrointestinal disorders, including IBS, targeting pathways that suppress inflammation and protect the mucosa. Wnt signaling is known to modulate NF-k $\beta$-dependent inflammatory cytokine production. This sparked the idea of evaluating the impact of STW 5 on the expression of inflammatory-response and Wnt/ $\beta$ catenin-target genes in an IBS-like model. Main methods: We used zebrafish and dextran sodium sulfate (DSS) treatment to model IBS-like conditions in vivo and in vitro and examined the effects of subsequent STW 5 treatment on the intestines of DSS-treated fish and primary cultured intestinal and neuronal cells. Gross gut anatomy, histology, and the expression of Wnt-signaling and cytokine genes were analyzed in treated animals and/or cells, and in controls. Key findings: DSS treatment up-regulated the expression of interleukin-8, tumor necrosis factor- $\alpha$, wnt $3 a$, and claudin- 1 in explanted zebrafish gut. Subsequent STW 5 treatment abolished both the macroscopic signs of gut inflammation, DSS-induced mucosecretory phenotype, and normalized the DSS-induced upregulated expression of il10 and Wnt signaling genes, such as wnt $3 a$ and $c l d n 1$ in explanted zebrafish gut. Under inflammatory conditions, STW 5 downregulated the expression of the pro-inflammatory cytokine genes $i l 1 \beta$, il6, ils, and $t n f \alpha$ while it upregulated the expression of the anti-inflammatory genes il10 and wnt3a in enteric neuronal cells in vitro. Significance: Wnt signaling could be a novel target for the anti-inflammatory and intestinal permeability-restoring effects of STW 5, possibly explaining its clinical efficacy in IBS.
\end{abstract}

Keywords: IBS; STW 5; NF-k $\beta$; Wnt signaling; claudin 1; wnt3a; zebrafish

\section{Introduction}

Irritable bowel syndrome (IBS) is one of the most common functional bowel disorders and is defined by chronic or recurrent abdominal pain, stool irregularities, and bloating [1-3] in the absence of known organic pathology.

IBS-related morpho-functional changes have been reported in both the intestinal epithelial barrier (e.g., goblet cell hyperplasia, increased paracellular permeability, lower expression of tight junctions, altered expression of claudins) and the enteric neuromuscular 
compartment (e.g., decreased muscle layer thickness, reduced entero-endocrine cell activity, altered circulating levels of serotonin (5-HT3)).

Currently, the management of IBS patients is complex and the available treatments for this functional disorder include pharmacological approaches combined with a healthy lifestyle. Among the treatment options, there are antispasmodics, antidepressants, opioid receptor agonists, 5-HT3 receptor antagonists, anti-inflammatory agents, antibiotics, probiotics, laxatives, and prosecretory agents [4,5]. Besides providing no definitive solution for IBS, these drugs cause remarkable adverse effects and/or show low efficacy in controlling multiple symptoms simultaneously [6-11]. As alternative options to chemically defined medications, herbal medicinal products have demonstrated efficacy in the treatment of functional bowel disorders [12]. Containing a variety of active components, they offer the advantage of targeting various underlying pathways but, similarly to traditional drugs, they may also cause adverse effects [13]. Thus, appropriate toxicological studies and pharmacovigilance programs are required to ensure that patients are not exposed to unjustifiable risks. Belonging to this class of medicines, STW 5 is a hydro-ethanolic liquid preparation composed of the nine medicinal herbs Iberis amara, Angelicae radix, Cardui mariae fructus, Chelidonii herba, Liquiritiae radix, Matricariae flos, Melissae folium, Carvi fructus, and Menthae piperitae folium. Several prospective, controlled clinical trials have confirmed the clinical efficacy of STW 5 in managing various functional gastrointestinal disorders, including functional dyspepsia and IBS [14-19]. Through several mechanisms of action [20,21], STW 5 has demonstrated the ability to induce (i) spasmolytic/tonicizing effects on intestinal smooth muscle, (ii) anti-inflammatory effects, (iii) pain reduction by modulating GI sensory afferent neuronal signaling, and (iv) regulation of the microbiome [16,22-24].

Growing evidence suggests that dysregulated activation of Wnt signaling in the enteric nervous system [25], stromal compartment [9,26], immune cells [27], and epithelium [28] is involved in various aspects of the pathogenesis of functional GI disorders, including visceral hypersensitivity, altered gut motility and low-grade gut inflammation [29]. Intersecting with major inflammatory pathways, the Wnt pathway has both anti- and pro-inflammatory effects in the gut. In particular, canonical Wnt downregulates NF-k $\beta$-dependent transcription of the interleukins (IL)-1 $\beta, I L-6, I L-8$, and tumor necrosis factor (TNF) $\alpha$ [30,31]. Moreover, as reported by Manicassamy et al. [32], the activation of $\beta$-Catenin in dendritic cells contributes to the switch from immunity to tolerance, stimulating the expression of the anti-inflammatory NF-k $\beta$ target gene IL-10. As previously reported by our group, the Wnt receptor Frizzled- 9 and its ligand Wnt3a are expressed in the rat myenteric plexus of the enteric nervous system (ENS) [25], and the alteration of adherent junctions in ENS cells in vitro induces an aberrant accumulation of $\beta$-Catenin [33]. In contrast, the activation of pro-inflammatory mediators seems to be dependent on the non-canonical Wnt pathway [34].

Considering that Wnt plays a role in the modulation of inflammatory cytokine production, such as through the NF-k $\beta$ signaling pathway [35], it is conceivable that STW 5 alleviates IBS by modulating the expression of inflammatory-response and Wnt-target genes. Testing this hypothesis for the first time, in this study we assessed in vivo and in vitro zebrafish models of IBS-like conditions induced by treatment with $0.5 \%$ dextran sodium sulfate (DSS) for $8 \mathrm{~h}$. Sharing numerous gut functions and immune genes with mammals, the zebrafish has been proposed as a model of intestinal inflammation and injury [36]. Based on the evidence acquired in our laboratory and previously reported [37], the inflammation induced by DSS for $8 \mathrm{~h}$ resembles the gastrointestinal alterations observed in IBS patients, such as (i) low-grade gut inflammation; (ii) goblet cell dysplasia; and (iii) upregulated transcription of both claudin1, as is typically observed in IBS-C patients [38,39], and wnt3a, as is commonly observed during gut inflammation [40]. 


\section{Results}

\subsection{In Vivo Model of IBS and Impact of STW 5 on Morphological Changes}

The macroscopic evaluation of selected intestine explants is presented in Figure 1A-D. Compared with their controls, DSS-treated zebrafish showed increased blood flow and accumulation of fluids (Figure 1A,B). In contrast, no signs of visceral inflammation were visible in samples isolated from zebrafish treated with STW 5 alone (Figure 1C) or in combination with DSS (Figure 1D). As an increased number of mucus-producing cells is commonly considered to indicate active inflammation, we counted the goblet cells in bulb, midgut, and hindgut explants. Goblet cells are mucus-secreting epithelial cells that act as the first line of defense against dangerous physical and chemical factors from ingested food, microbes, and microbial products [41,42]. As previously reported by Cheng et al. [43], small intestine and colon samples of patients with constipation- or diarrhea-predominant IBS exhibit changes in goblet cells and altered mucus secretion. In our study, STW 5 treatment reversed the inflammatory response by reducing the numbers of goblet cells in the bulb, midgut, and hindgut to the levels detected in control samples (Figure 1E-J). The overall organization of the enteric nervous system, connective tissue, and smooth muscle layers in zebrafish intestine is comparable to that of mammals, though the former has a less complex lamina propria and lacks a submucosa [44]. Here, immunofluorescence revealed Frizzled-9 in both the epithelium and the muscle layer (Figure 2A) of the zebrafish gut. Interestingly, Frizzled-9 co-localized with the PAN-neuronal marker (Figure 2B,C), suggesting it is expressed in myenteric neurons. As shown in Figure 2D, Wnt3a was distributed within the epithelial and muscle layers, providing evidence that epithelial cells (Epc) and ENS cells (Figure 2E-H) are responsive to canonical Wnt signaling.
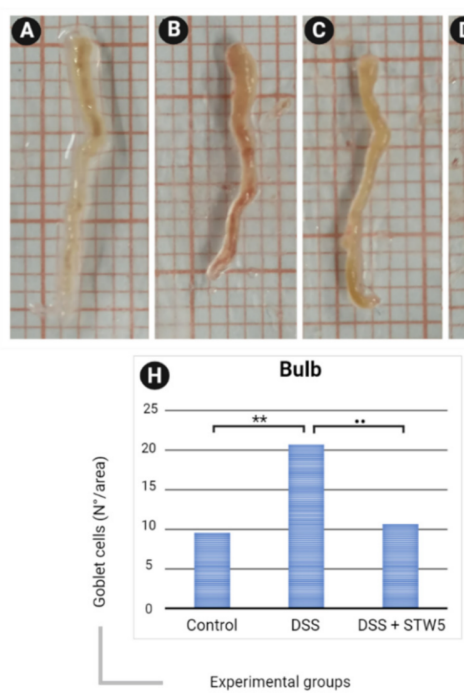
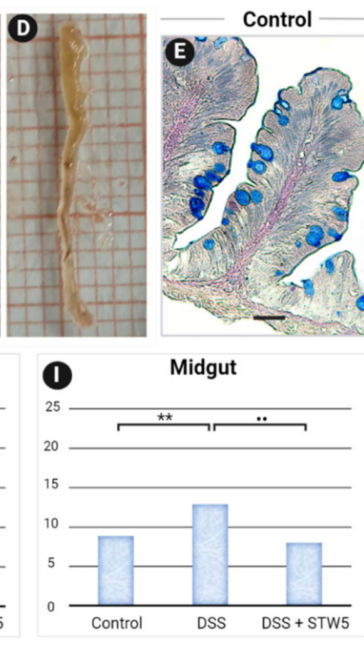
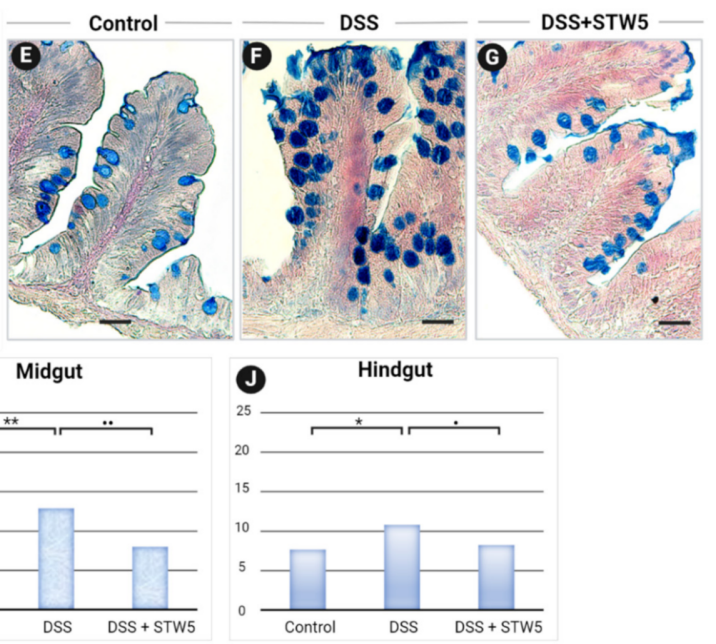

Figure 1. Macroscopic features of gut explants from zebrafish under (A) resting conditions, (B) after $8 \mathrm{~h}$ of treatment with $0.5 \%$ dextran sodium sulfate (DSS), (C) after $16 \mathrm{~h}$ of treatment with $0.12 \mathrm{mg} / \mathrm{Ml}$ STW 5, and (D) after DSS + STW 5 treatment. (E-G) Tissue sections of zebrafish gut (bulb) stained with Alcian blue showing the distribution and density of goblet cells (blue) under resting conditions, DSS- or DSS+STW5-treatment. (H-J) Relative number of goblet cells in bulb, midgut, and hindgut explants. The quantification was performed using five different slides of each part of the intestine from three animals ( $n=15$ sections total for bulb, midgut, and hindgut). Data are expressed as the mean number of goblet cells \pm standard deviation (SD). Statistical significance was calculated using the Wilcoxon test comparing DSS-treated or DSS+STW 5-treated samples with controls. ${ }^{*} p \leq 0.05$; ${ }^{* *} p \leq 0.01$. DSS+STW 5 -treated samples vs. DSS $(\bullet p \leq 0.05 ; \bullet p \leq 0.01)$. 

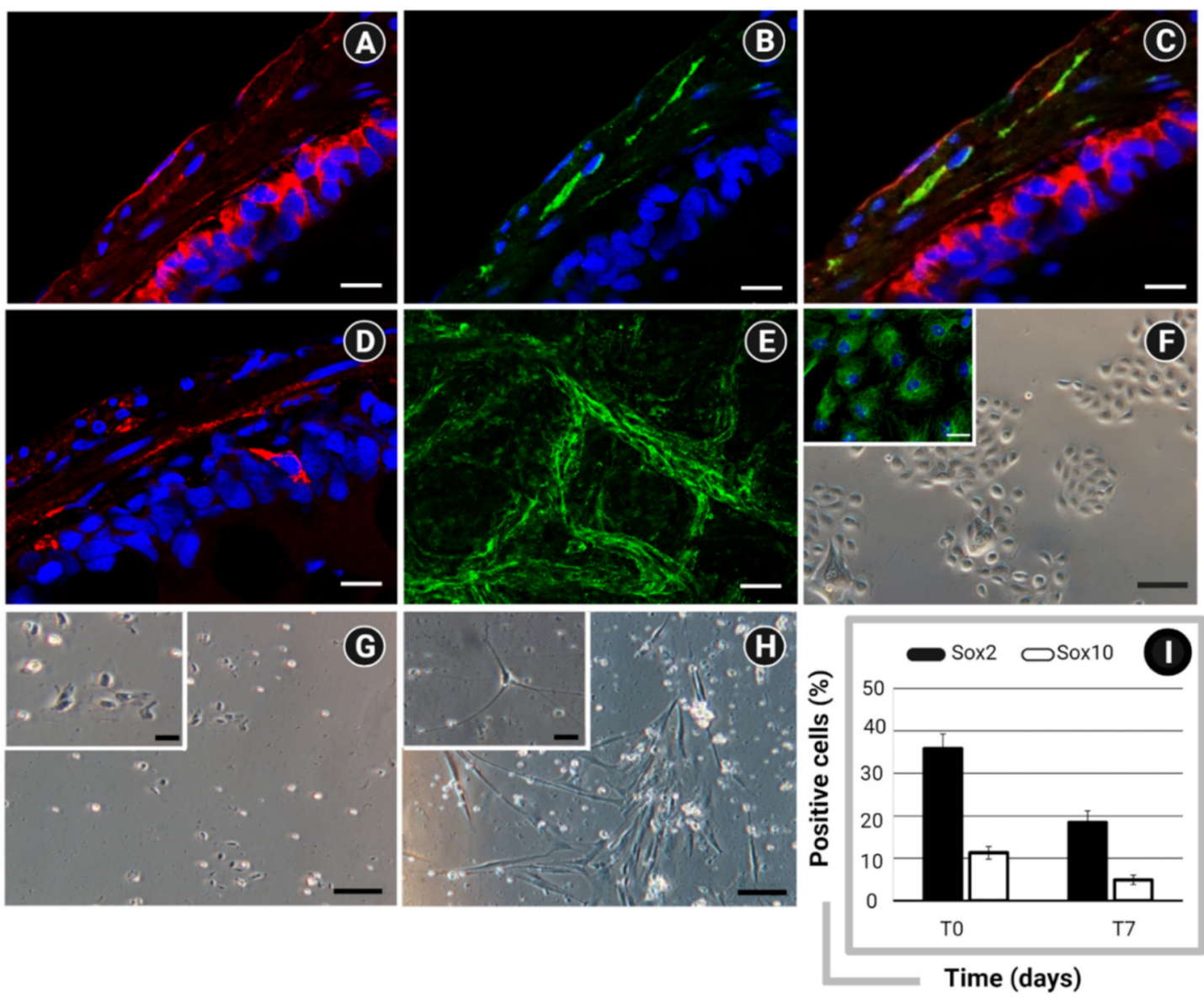

Figure 2. Immunofluorescent staining showing the expression of (A) Frizzled 9 (red) within the epithelial and neuromuscular compartments; (B) PAN neuronal marker (green) within the neuromuscular layer; and (C) both markers (Frizzled 9 and PAN neuronal marker) in colocalization (yellow); and (D) Wnt3a within the epithelium and neuromuscular layer. Nuclear counterstaining was performed using DAPI (blue). (E) Whole-mount immunofluorescent staining of zebrafish ENS network by detection of PAN neuronal marker (green) Bar: $50 \mu \mathrm{m}$. Optical microscopy of (F) primary intestinal epithelial cells, characterized by the expression of Pan-cytokeratin (left corner, green); ENS cultures at (G) $24 \mathrm{~h}$ and (H) 7 days from isolation. Bar: $100 \mu \mathrm{m}(200 \mu \mathrm{m}$ in left corner). (I) Flow cytometry analysis of Sox2 and Sox10 in ENS cells at the time of isolation (T0) and after culturing for 7 days (T7). Data are expressed as percentage (\%) of positive cells \pm standard deviation (SD). Created with BioRender.com, accessed on 31 October 2021.

\subsection{In Vitro Models of IBS}

In vitro models of IBS-like conditions were assessed, and culture conditions were defined to preserve cellular functionality. EP cells exhibited a typical organization in colonies, polygonal shape, and cytokeratin expression (Figure 2F). Freshly isolated ENSc included both immature (Figure 2G) and mature (Figure $2 \mathrm{H}$ ) cells. Flow cytometry revealed specific immunoreactivity for Sox 2 , a known marker of neuronal progenitors $[45,46]$, and Sox10, a marker of neural crest cells [47] (Figure 2I).

\subsection{In Vivo Response to STW 5}

Several studies have investigated mucosal levels of cytokines in IBS patients. In vitro and in vivo experiments have demonstrated that the secretion of IL-10, an anti-inflammatory cytokine, is depressed at baseline, while IL-1 $\beta$, IL-6, IL-8, IL-12, and TNF- $\alpha$ are elevated. The treatment of zebrafish with $0.5 \%$ DSS for $8 \mathrm{~h}$ (Figure 3A) induced an inflammatory state characterized by increased $i l 8, \operatorname{tnfa}, \operatorname{cldn1} 1$, and wnt3A mRNA levels. No significant changes were observed in the mRNA levels of il6 or il10. The inflammatory response is critical for fighting insults such as pathogen invasion or tissue damage, but if inflammation 
becomes chronic it is often detrimental to the host. Accordingly, the balance between protective and degenerative inflammation is gaining attention from a therapeutic point of view [48]. Several mechanisms operate to ward off exaggerated neuroimmune responses or to appropriately enhance a protective immune response [49]. One of these mechanisms is the production of anti-inflammatory cytokines, such as IL-10. Under the IBS-like conditions induced by DSS, il10 and Wnt signaling genes, such as wnt3a and $c l d n 1$, were negatively regulated by STW 5 treatment. This observation highlights the ability of STW 5 to favor the resolution of inflammatory processes that interact with both Wnt signaling and the $\mathrm{NF}-\mathrm{k} \beta$ pathway.
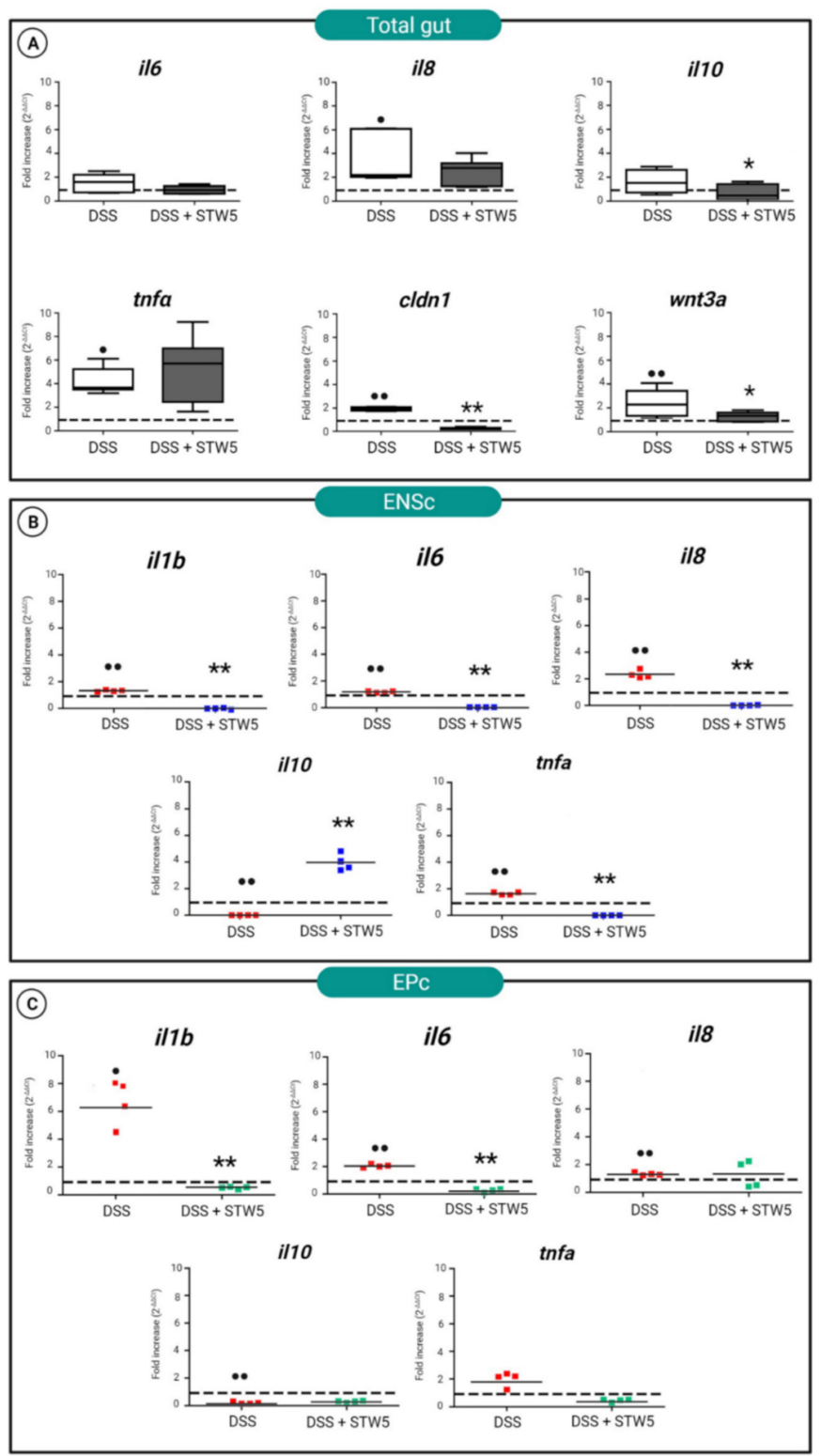

Figure 3. (A) Quantitative PCR analysis of $i l 6$, ils, il10, tnfa, wnt3a, and $c l d n 1$ genes in explanted zebrafish total guts. The tissues were explanted from animals treated for $8 \mathrm{~h}$ with DSS (controls) or incubated with STW 5 for $16 \mathrm{~h}$ after DSS stimulation. qRT-PCR of $i l 6$, ils, il10, and tnfa in (B) ENS cultures (ENSc), and (C) epithelial cells (EPc). Expression levels were determined as relative to the expression of the housekeeping gene ef $1 \alpha$, normalized to controls, and calculated using the $\Delta \Delta \mathrm{Ct}$ method based on the equation $2^{-\Delta \Delta C t} \pm$ standard deviation. In the graphs, the expression level of controls was set to 1 and indicated with a dotted line. Statistical significance was calculated using the Wilcoxon test. Samples vs. controls $(\bullet p \leq 0.05 ; \bullet p \leq 0.01)$. Samples vs. DSS $\left({ }^{*} p \leq 0.05 ;{ }^{* *} p \leq 0.01\right)$. 


\subsection{In Vitro Molecular Efficacy of STW 5}

To better understand the protective effect of STW 5 in IBS through a modulation of Wnt signaling, we investigated the specific immune response of EP and ENS cells, using qRT-PCR. In primary ENS cell cultures, DSS-mediated induction of IBS-like conditions promoted an inflammatory state driven by the activated expression of NF-k $\beta$ target genes, including $i l 1 \beta, i l 6, i l 8$, and $\operatorname{tnf} \alpha$ (Figure 3B). In parallel, we detected a significant reduction in the level of $i l 10$ mRNA. In DSS-induced cells, STW 5 treatment negatively regulated $(p \leq 0.01)$ the expression of the pro-inflammatory cytokine genes $i l 1 \beta, i l 6, i l 8$, and $\operatorname{tnf} \alpha$, and in parallel increased the expression of the anti-inflammatory gene il10.

The attenuation of the inflammatory response exerted by STW 5 was less effective in EPc (Figure 3C). After DSS treatment, EPc levels of $i l 1 b$, il6, and il8 mRNAs increased, while their expression of $i l 10$ was significantly reduced. STW 5 treatment induced a defensive effect, reducing the expression of the pro-inflammatory cytokines $i l 1 b$ and $i l 6$.

\section{Discussion}

IBS is a heterogeneous multifactorial disorder driven by environmental, psychosocial, and genetic factors [50]. Here we used in vivo and in vitro zebrafish IBS models to investigate whether STW 5 modulates the expression of Wnt target genes. Considering the important roles of the epithelium, connective tissue compartment, and enteric nervous system in the development of disease susceptibility, zebrafish models have the following advantages: they (i) reduce the cost of research, (ii) enable the investigation of innate immunity due to a delayed maturation of adaptive immunity, (iii) allow easy temporal control over microbial and chemical interventions, and (iv) allow host-microbe interactions to be manipulated for a better understanding of the pathogenesis of gut inflammatory diseases [51]. Chassaing et al. [52] and Scanzi et al. [37] have treated mice with $0.5 \%$ DSS in drinking water to impair intestinal homeostasis. In our experiments, zebrafish were treated for only $8 \mathrm{~h}$, to avoid severe inflammation. As confirmed by macroscopic examination and qRT-PCR analyses, the animals responded to DSS by developing intestinal redness, swelling, inflammation, and increased ils, tnfa, and wnt3a mRNA levels. In both EPc and ENSc, the expression of the inflammatory gene il 6 was also increased, confirming the activation of the inflammatory system or a diminished ability to suppress it. Furthermore, as already observed in the small intestine and colonic mucosa of constipation-predominant IBS patients [37], up-regulated expression of $c l d n 1$ mRNA was observed in our study, suggesting a structural alteration similar to that observed in the small intestine and colonic mucosa of constipation-predominant IBS [43].

Cytokine imbalance is a biological marker of IBS [53-55]. High levels of IL-1b, IL-6, IL-8, and TNF- $\alpha$ are detected in peripheral blood mononuclear cells in IBS-C and IBSD [56-59]. In particular, IL-6 exerts its activity by (i) stimulating submucosal secretomotor neurons [60,61]; (ii) modulating mucosal ion transport; and (iii) regulating epithelial permeability [62,63]. As reported by Dinan et al. [59], the cholinergic system could be involved in increased release of IL-6 in the colon of IBS patients. The chemokine IL-8, which is elevated in human IBS plasma $[56,64]$, acts as a neuromodulator and affects the function of colonic neurons by increasing intracellular $\mathrm{Ca}^{2+}$. Both IL-6 and IL-8 stimulate gut contractions in response to alterations in colonic tight junction proteins [65]. In turn, the altered expression of claudins, such as claudin 1 [66], contributes to the dysfunction of the intestinal epithelial barrier and promotes increased gut permeability in IBS patients. The inhibition of IL-6 and IL-8 signaling has been demonstrated to normalize visceral pain sensitivity in a rat IBS model [65].

Our experiments demonstrate that STW 5 is able to reduce the mRNA levels of proinflammatory cytokines $i l-1 b$, tnf- $\alpha$ il-6, or il-8 in zebrafish neuronal and epithelial cells, or explanted gut similar to previous findings from different cell types and models $[20,67]$. Neutralizing IL-6 and IL-8 attenuates evoked neuronal myenteric responses, altered GI motility, and visceral pain sensitivity in an IBS model [65]. Here, the anti-inflammatory activity of STW 5 was also indicated by the restoration of the DSS-induced activity of goblet 
cells and the normalization of their macroscopic appearance. Therefore, the clinical efficacy of STW 5 demonstrated in IBS could be mediated, at least in part, by this neutralizing effect on pro-inflammatory cytokines.

In the current study, DSS exposure resulted in the upregulation of cldn1 gene expression in explanted zebrafish gut, suggesting that a structural alteration occurs with IBS inflammation. These findings support a relevant link between inflammation and CLDN1 expression in IBS. Cheng et al. [43] demonstrated increased CLDN1 in the small intestine and colonic mucosa of patients affected by constipation-predominant IBS. This association suggests that the DSS model proposed in the present study can be effective in simulating some forms of IBS, as the upregulation of CLDN1 mRNA led to reduced intestinal permeability and resulted in constipation in patients.

Notably, CLDN1 has been described as a target gene for Wnt3a/ $\beta$-catenin/TCF signaling $[43,68,69]$. This modulatory activity could explain STW 5-induced downregulation of $c l d n 1$ observed as a result of the negative regulation of wnt3a shown in our study. This observation supports the hypothesis that Wnt signaling could be a novel target for the STW 5 herbal preparation.

The interplay between the intestinal epithelial barrier and neuromuscular compartment gives rise to a dynamic network that preserves GI physiology and gut microenvironment integrity. IL-10 plays a critical role in preventing inflammatory and autoimmune pathologies by limiting the immune response to pathogens and microbial flora [70]. IL-10 is a target gene of NF-k $\beta$ and, in response to an inflammatory insult, is transcriptionally upregulated by nuclear translocation of the p50 transcription factor. Accordingly, restoration exerted by STW 5 on the DSS-induced upregulation of $i l 10$ expression in the explanted gut could indicate a protective activity that balances the host immune response and the epithelial secretory activity. In line with this evidence, our data showed that the number of goblet cells accumulating mucus was reduced by STW 5 in different regions of the gut, as previously reported [71,72]. The differential, cell-specific effect of STW 5 was clearly observed in its ability to promote the expression of il10 in ENS cells to balance the immune response and regulate neuronal excitability.

Taken together, these data identify novel targets for STW 5 that substantiate and could explain its clinically proven efficacy in treating IBS symptoms.

\section{Materials and Methods}

\subsection{Herbal Preparation}

Lyophilized STW 5 (5.7 g percent dry residue, batch number 430,392) was generously provided by Steigerwald Arzneimittel GmbH (Bayer Consumer Health, Darmstadt, Germany). The quality of this batch complied with the quality prerequisites for STW 5 (Kroll and Cordes, 2006). STW 5 lyophilisate was dissolved in water and used at the final concentration of $0.12 \mathrm{mg} / \mathrm{mL}$, based on our preliminary studies (data not reported) and demonstrated as effective to induce anti-inflammatory effects starting from $16 \mathrm{~h}$ of treatment.

\subsection{Animals}

Adult zebrafish (Danio rerio, $n=41$ males, aged 6 months) were housed and fed as described by Aleström et al. [73]. The environment was maintained at $28.5^{\circ} \mathrm{C}$ with a $12 \mathrm{~h}$ light:dark cycle. The study design is illustrated in Figure 4. 


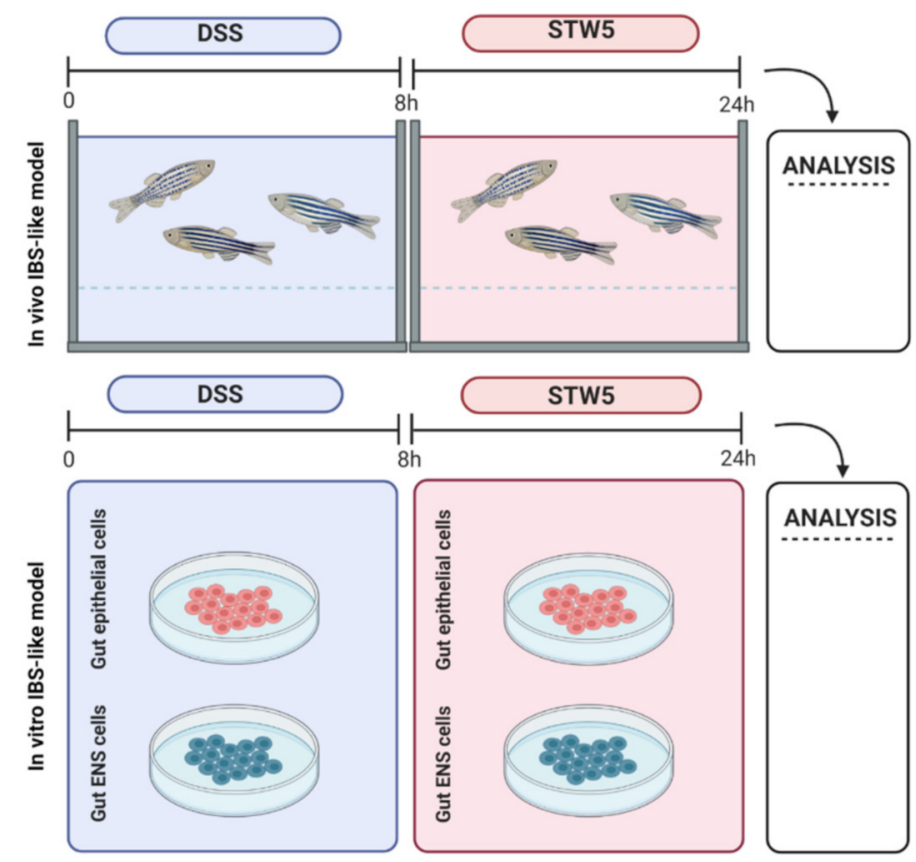

Figure 4. Experimental scheme to obtain in vivo and in vitro models of irritable bowel syndrome (IBS) (created with BioRender.com, accessed on 21 May 2021). (Top) In vivo treatment: IBS was induced in zebrafish with $0.5 \%$ dextran sodium sulfate (DSS) in the water. The water was exchanged after $8 \mathrm{~h}$, a mixture of nine medicinal herbs (STW 5) was added to a concentration of $0.12 \mathrm{mg} / \mathrm{mL}$, (dissolved in water), and the fish were kept in this for $16 \mathrm{~h}$. The gut was explanted for examination. (Bottom) In vitro treatment: The intestine from wild-type zebrafish was dissected and digested to obtain cells from the epithelial compartment (EPc) and myenteric plexus (ENSc). After induction of IBS-like inflammation with $0.5 \%$ DSS for $8 \mathrm{~h}$, EPc and ENSc were treated for $16 \mathrm{~h}$ with $0.12 \mathrm{mg} / \mathrm{mL}$ ethanol-free, lyophilized STW 5 resuspended in FBS-deprived culture medium.

\subsection{Investigation of Canonical Wht Components in Zebrafish Gut}

To demonstrate that STW 5 suppresses inflammation by modulating $\beta$-catenin signaling, a preliminary analysis using immunofluorescence was performed on full-thickness gut wall preparations to detect the expression patterns of Wnt components (i.e., Fzd9 and Wnt3a) in neuronal and non-neuronal compartments. Intestine explants were fixed overnight in BD Cytofix Fixation Buffer (Becton Dickinson Biosciences, San Jose, CA, USA), and embedded in paraffin wax (Carlo Erba, Milan, Italy). Sections of 5- $\mu$ m thickness were prepared using a Histoslide 2000 microtome (Leica Microsystems, Wetzlar, Germany). After deparaffinization in xylene and rehydration, the samples were immersed in citrate buffer ( $\mathrm{pH} 6$ ) and treated four times ( $5 \mathrm{~min} / \mathrm{each}$ ) with microwave irradiation. Next, the sections were blocked in $10 \%$ bovine serum albumin (BSA) for $2 \mathrm{~h}$ at room temperature (RT). To detect target proteins, the samples were incubated with primary polyclonal antibodies against PAN neuronal marker (Merck Millipore, Billerica, MA, USA), Fzd9, and Wnt3a (both from Immunological Sciences, Rome, Italy), followed by staining with Alexa Fluor 488-conjugated or Alexa Fluor 594-conjugated secondary antibodies (Thermo Fisher Scientific, Darmstadt, Germany) (Table 1). For intracellular markers, membrane permeabilization was performed with $0.2 \%$ Triton X-100 for $30 \mathrm{~min}$ before the incubation with antibodies. Secondary antibody-matched negative controls were prepared as reference. Data were acquired using a DM2000 microscope (Leica Microsystems, Wetzlar, Germany). 
Table 1. Antibodies used in flow cytometry and immunofluorescence studies to investigate the effects of STW 5 in zebrafish IBS. Due to the high genomic similarity of zebrafish with human, with zebrafish sharing $70 \%$ of their genes with humans, anti-human antibodies were used to detect fish markers when no specific antibodies were available. AF: Alexa Fluor; FZD9: Frizzled 9, a Wntsignaling receptor; PAN cytokeratin: epithelial cell marker; PAN neuronal: neurofilament marker; PE: phycoerythrin; Sox2: transcription factor; WNT: signaling protein involved in inflammation.

\begin{tabular}{cc}
\hline Primary Antibody & Manufacturing Company \\
\hline Rabbit anti-FZD9 & Immunological Sciences \\
\hline Rabbit anti-WNT3A & Immunological Sciences \\
\hline Mouse anti-PAN Neuronal & Merck Millipore \\
\hline Mouse anti-PAN Cytokeratin & Abcam \\
\hline Mouse anti-Sox2 & Santa Cruz Biotechnology \\
\hline Rabbit anti-Sox10 & Santa Cruz Biotechnology \\
\hline Secondary antibody & Invitrogen \\
\hline Goat anti-rabbit AF488 & Invitrogen \\
\hline Goat anti-mouse AF594 & Santa Cruz Biotechnology \\
\hline Goat anti-rabbit PE & Santa Cruz Biotechnology \\
\hline Goat anti-mouse PE &
\end{tabular}

\subsection{Assessment of Zebrafish Models of IBS}

\subsubsection{In Vivo Model}

The IBS-like model was induced by placing adult male zebrafish into individual tanks containing $0.5 \%$ dextran sodium sulfate (Sigma-Aldrich, St. Louis, MO, USA) for $8 \mathrm{~h}[37,74]$. After a water change, the animals were treated with $0.12 \mathrm{mg} / \mathrm{mL}$ STW 5 for $16 \mathrm{~h}$, and then anesthetized with tricaine $(0.16 \mathrm{mg} / \mathrm{mL}, \mathrm{E} 10521$, Sigma $)$ and sacrificed by decapitation for gut explant. The establishment of a functional in vivo IBS model was evaluated through macroscopic examination of the intestine, histochemistry, and expression analysis of genes associated with general inflammation (wnt3a), IBS (il1 $\beta, i l 6, i l 8, \operatorname{tnf\alpha }$ ) [75], intestinal permeability (cldn1) [76], and immune regulation (il10) [77]. Animals kept under resting conditions were used as controls.

\section{Histochemistry}

To evaluate mucous accumulation, $5-\mu \mathrm{m}$ thick slices from the bulb, midgut, and hindgut of untreated (control), DSS- or DSS+STW 5-treated animals were incubated with $1 \%$ Alcian blue (Sigma-Aldrich, St. Louis, MO, USA) in 3\% acetic acid (pH 2.5; SigmaAldrich, St. Louis, MO, USA) for $30 \mathrm{~min}$. Nuclear counterstaining was performed by treating with $0.1 \%$ nuclear fast red (Sigma-Aldrich, St. Louis, MO, USA) for $5 \mathrm{~min}$. After dehydration in ethanol, the sections were cleared with xylene and mounted with Pertex mounting medium (Leica Microsystems, Wetzlar, Germany). As an increased number of mucus-producing cells is commonly considered to indicate active inflammation, we counted the goblet cells in bulb, midgut, and hindgut explants. The quantification was performed using five different slides of each part of the intestine from three animals $(n=15$ sections total for bulb, midgut, and hindgut). Data were expressed as the mean number of goblet cells \pm standard deviation (SD). Statistical significance was calculated using the Wilcoxon test, comparing DSS-treated or DSS+STW 5-treated samples with controls.

\section{qRT-PCR}

When STW 5 treatment was completed, intestines were collected in BeadBug prefilled tubes (Sigma-Aldrich, St. Louis, MO, USA) containing $1 \mathrm{~mL}$ of TRI Reagent solution (Zymo Research, Irvine, CA, USA). Tissues were mechanically disrupted, and total RNA 
was extracted according to the manufacturer's instructions. The amount of total RNA was evaluated by measuring the absorbance at $260 \mathrm{~nm}$ with a Nanodrop 2000 (Thermo Fisher Scientific, Waltham, MA, USA). For mRNA purification, $3 \mu \mathrm{g}$ of each total RNA sample was purified using a Dynabeads mRNA DIRECT kit (Thermo Fisher Scientific, Waltham, MA USA). Quantitative RT-PCR was performed in a one-step procedure using a Magnetic Induction Cycler (MIC) PCR machine (Bio Molecular Systems, Australia), qPCR SyGreen 1-step Go Lo Rox (PCR Biosystems Ltd., London, UK), 7.5 ng of mRNA, and the oligonucleotides (Thermo Fisher Scientific, Waltham, MA, USA) listed in Table 2. The housekeeping gene eukaryotic translation elongation factor 1 alpha $1(e f 1 \alpha)$ was used as an internal control. Relative gene expression levels (i.e., fold changes normalized to controls) were quantified using the comparative $\mathrm{Ct}$ method $\left(2^{-\Delta \Delta C t}\right)$. Each target gene was evaluated in triplicate, and three independent experiments for each study group were executed. Significance was determined using the Wilcoxon test, comparing the DSS+STW 5 samples to DSS-treated samples or controls.

Table 2. Oligonucleotide primers used for quantitative RT-PCR analysis of gene regulation in response to STW 5 treatment in irritable bowel syndrome. F: forward; R: reverse.

\begin{tabular}{|c|c|c|c|}
\hline Gene Name & & Primer Sequence $\left(5^{\prime}-3^{\prime}\right)$ & Accession Number \\
\hline $\begin{array}{l}\text { eukaryotic translation elongation } \\
\text { factor } 1 \text { alpha }\end{array}$ & ef $1 \alpha$ & $\begin{array}{l}\text { F: TTCGAGAAGGAAGCCGCTG } \\
\text { R: CAGCAACAATCAGCACAGCAC }\end{array}$ & AY422992 \\
\hline wnt family member 3A & wnt $3 A$ & $\begin{array}{l}\text { F: GGCGACTACATGAAGGACAA } \\
\text { R: TACTTTGGCCGTAGGGTTTC }\end{array}$ & AY613787.1 \\
\hline claudin 1 & $\operatorname{cldn1}$ & $\begin{array}{l}\text { F: CGCCACAGGTGAAGAGTAAA } \\
\text { R: CCTCGCGTTAGTTGGAGTAAA }\end{array}$ & NM_131770.1 \\
\hline tumor necrosis factor $\alpha$ & $\operatorname{tnf} \alpha$ & $\begin{array}{c}\text { F: CCGTCTGCTTCACGCTCC } \\
\text { R: GTCTTTGATTCAGAGTTGTATCC }\end{array}$ & AY427649.1 \\
\hline interleukin 8 & $i l 8$ & $\begin{array}{l}\text { F: TGTTTTCCTGGCATTTCTGACC } \\
\text { R: TTTACAGTGTGGGCTTGGAGGG }\end{array}$ & XM_009306855 \\
\hline interleukin 6 & $i l 6$ & $\begin{array}{l}\text { F: GCTACACTGGCTACACTCTTC } \\
\text { R: GAGACTCTTTACGTCCACATCC }\end{array}$ & NM_001261449.1 \\
\hline interleukin 10 & $i l 10$ & $\begin{array}{c}\text { F: CTCTGCTCACGCTTCTTCTT } \\
\text { R: GCTCCCTCAGTCTTAAAGGAAA }\end{array}$ & NM_001020785.2 \\
\hline interleukin $1 \beta$ & $i l 1 \beta$ & $\begin{array}{c}\text { F: GACATGCTCATGGCGAACG } \\
\text { R: GCAAATCGTGCATTGCAAGACG }\end{array}$ & AY340959.1 \\
\hline
\end{tabular}

\subsubsection{In Vitro Models}

Published protocols for isolating intestinal cells from adult zebrafish are currently lacking. We devised a method to isolate epithelial and myenteric plexus cells from zebrafish gut by adapting a standardized procedure [78]. Briefly, animals were anesthetized by immersion in tricaine solution. After decapitation, the whole gut was extracted under a dissecting microscope. The surrounding mesentery, fat, and feces were removed, and the remaining tissues were washed several times in phosphate-buffered saline containing $2 \%$ antibiotic/fungizone solution (Sigma-Aldrich, St. Louis, MO, USA). Afterwards, the tissues were digested in 4 U Dispase type II solution (Roche, Basel, Switzerland) for 40 $\min$ at $28^{\circ} \mathrm{C}$. The samples were then differently processed for (i) the isolation of epithelial cells (EPc), (ii) the morphological characterization of the enteric nervous system (ENS) by whole-mount immunofluorescent staining, and (iii) the isolation of ENS-derived cells (ENSc).

\section{EP Cell Cultures}

The epithelium was collected from samples digested with 4 U Dispase II solution and then incubated in Accumax solution (Sigma-Aldrich, St. Louis, MO, USA) for 30 min at $28{ }^{\circ} \mathrm{C}$. After tissue dissociation with gentle pipetting, the samples were centrifuged at $1200 \mathrm{rpm}$ for $5 \mathrm{~min}$, and the pelleted cells were used to seed glass coverslips coated 
with $10 \mu \mathrm{g} / \mathrm{cm}^{2}$ collagen IV (Sigma-Aldrich, St. Louis, MO, USA) in Dulbecco's modified Eagle medium supplemented with high glucose (Lonza, Basel, Switzerland), 10\% FBS, $0.25 \mathrm{U} / \mathrm{mL}$ insulin (Sigma-Aldrich, St. Louis, MO, USA), 1\% L-glutamine (Sigma-Aldrich, St. Louis, MO, USA), $1 \%$ antibiotic/fungizone solution, and $10 \mathrm{ng} / \mathrm{mL}$ epidermal growth factor. Images of EP cultures were acquired using a DM2000 microscope (Leica Microsystems, Wetzlar, Germany) equipped with a Nikon Digital Sight DS-5Mc camera (Nikon Corporation, Tokyo, Japan).

Whole-Mount Immunofluorescent Staining

After digestion with Dispase II (Sigma-Aldrich, St. Louis, MO, USA), the muscle layer of the intestine was fixed with BD Cytofix Fixation Buffer overnight at $4{ }^{\circ} \mathrm{C}$. For immunofluorescent staining, the samples were permeabilized with 0.5\% Triton X-100 (Sigma-Aldrich, St. Louis, MO, USA) for 30 min following a blocking step with 10\% BSA for $1 \mathrm{~h}$ at RT. Samples were incubated with primary antibody against PAN neuronal marker (Merck Millipore, Billerica, MA, USA) and an Alexa Fluor 488-conjugated secondary antibody. After mounting in Fluoro-Gel II solution containing 4',6-diamidino-2-phenylindole (DAPI) (Fisher Molecular Biology, Trevose, PA), the samples were analyzed using a Leica TCS SP5 confocal microscope (Leica Microsystems, Wetzlar, Germany).

\section{ENS Cell Cultures}

When collected as described above, the muscle layer was treated with $5 \mu \mathrm{g} / \mathrm{mL}$ collagenase II, $200 \mu \mathrm{g} / \mathrm{mL}$ DNAse (Roche, Basel, Switzerland), and $50 \mathrm{ng} / \mathrm{mL}$ trypsinchymotrypsin inhibitor (Sigma-Aldrich, St. Louis, MO, USA) in Hank's buffered saline solution for $50 \mathrm{~min}$ at $28^{\circ} \mathrm{C}$. The cells and remaining undigested tissues were then centrifuged at $800 \mathrm{rpm}$ for $5 \mathrm{~min}$. The pellet was incubated in AccuMax solution for $20 \mathrm{~min}$ at $28^{\circ} \mathrm{C}$. Finally, the samples were cultured in ENS culture medium composed of NeurobasalA (Gibco, Billings, MT, USA), 2\% neuronal stem cell supplement (Gibco, Billings, MT, USA), 1\% BSA (Sigma-Aldrich, St. Louis, MO, USA), 5\% FBS (Thermo Fisher Scientific, Darmstadt, Germany), 0.1\% B-mercaptoethanol (Thermo Fisher Scientific, Darmstadt, Germany), 1\% L-glutamine (Sigma-Aldrich, St. Louis, MO, USA), and 1\% antibiotic/fungizone solution. To optimize the in vitro cell growth, culture medium was supplemented with $10 \mathrm{ng} / \mathrm{mL}$ epidermal growth factor, $20 \mathrm{ng} / \mathrm{mL}$ basic fibroblast growth factor, and $10 \mathrm{ng} / \mathrm{mL}$ glial cell line-derived neurotrophic factor (all from ImmunoTools, Friesoythe, Germany). Twenty-four hours after isolation, the medium was replaced with fresh medium without FBS and the cells were cultured for 7 days at $28{ }^{\circ} \mathrm{C}$ in a $5 \% \mathrm{CO}_{2}$ atmosphere at $95 \%$ humidity. Optical microscopy images were acquired using a DM2000 microscope (Leica Microsystems, Wetzlar, Germany) equipped with a Nikon Digital Sight DS-5Mc camera (Nikon Corporation, Tokyo, Japan).

\section{Morphological and Immunophenotypic Characterization of EPc and ENSc}

Primary EPc and ENSc morphology were analyzed using optical microscopy. After fixation in BD Cytofix Fixation Buffer, EPc were characterized by immunofluorescence for the expression of cytokeratins using anti-Pan Cytokeratin antibody (Abcam, Cambridge, UK) and Alexa Fluor 488-conjugated secondary antibody (Thermo Fisher Scientific, Darmstadt, Germany) (Table 1). ENSc were indirectly stained with primary antibodies against Sox2, Sox10, and a phycoerythrin-conjugated secondary antibody (Table 1). Data were acquired using a BD FACSCanto ${ }^{\mathrm{TM}}$ II Flow cytometer (Becton Dickinson Biosciences, San Jose, CA, USA) and FACSDiva v6.1.3 software (Becton Dickinson Biosciences, San Jose, CA, USA). In parallel, controls were prepared by omitting the primary antibody. Results were analyzed using FlowJo software and were presented as percent positive \pm standard deviation (SD). 
Impact of STW 5 on EPc and ENSc

Zebrafish gut cultures were treated with $0.5 \%$ DSS for $8 \mathrm{~h}$ to induce IBS-like inflammation. After DSS removal, some samples were cultured for $16 \mathrm{~h}$ with $0.12 \mathrm{mg} / \mathrm{mL}$ ethanol-free lyophilized STW 5 resuspended in FBS-deprived culture medium. In parallel, cells treated with DSS for $8 \mathrm{~h}$ and then kept in standard culture medium were used as controls. All samples were examined for the expression of inflammatory mediator genes (il1b, il6, il8, il10, and $t n f \alpha)$ as described earlier under qRT-PCR in Section 4.4.1. The analysis of data from four representative EPc and ENSc populations was performed as described above.

\subsubsection{Statistical Analysis}

Data were presented as means \pm standard deviation (SD). Statistical differences were calculated using the Wilcoxon test, comparing DSS-treated or DSS+STW 5-treated samples with controls. Results were considered significantly different at $p \leq 0.05$.

\section{Conclusions}

To our knowledge, this study is the first to suggest that the regulation of Wnt signaling could be a novel mechanism by which STW 5 exerts anti-inflammatory and intestinal permeability-restoring effects. This pharmacological activity is postulated to be dependent on the ability of STW 5 to regulate the expression of $c l d n 1$ and wnt3a and interfere with Wnt signaling, without affecting their physiological roles in normal tissues.

Author Contributions: M.P.: conceptualization, investigation, formal analysis, manuscript review, and editing. N.F.: conceptualization, investigation, formal analysis. S.S. and M.G.: conceptualization, investigation, formal analysis. S.P.: manuscript review and editing. R.M.A.: conceptualization, formal analysis, validation, manuscript review, and editing. S.R.: conceptualization, manuscript review, and editing. L.D.V.: supervision, funding acquisition, conceptualization, formal analysis, manuscript review, and editing. R.D.L.: supervision, funding acquisition, project administration, conceptualization, formal analysis, writing the original draft, manuscript draft writing, manuscript review, and editing. All authors have read and agreed to the published version of the manuscript.

Funding: This study was funded by Bayer Consumer Health, Steigerwald Arzneimittelwerk GmbH, Darmstadt, Germany. The funding did not in any way influence the outcome or any part of the study. The collaboration with Professor Pathak Surajit was supported by the Executive Program for Scientific and Technological Cooperation between the Italian Republic and the Republic of India (In17mo05).

Institutional Review Board Statement: All experiments were performed in accordance with the guidelines of European Communities Council Directive (2010/63) [73] and approved by the Animal Ethics Committee of the University of Padova (Italy) and the Italian Ministry of Health (Authorization Number 1101/2016-PR).

Informed Consent Statement: Not applicable.

Data Availability Statement: Data is contained within the article.

Acknowledgments: A special thanks to the Leukemia-Lymphoma-Myeloma Onlus Association, Section of Treviso (Italy), and I.R.A. Istituto Ricerche Applicate S.p.A., Usmate Velate (Italy) for providing the BD FACSCanto ${ }^{\mathrm{TM}}$ II Flow Cytometer and the MIC Real-Time PCR cycler, respectively.

Conflicts of Interest: The authors declare no conflict of interest.

\section{Abbreviations}

AF: Alexa Fluor; CLDN: Claudin; DSS: Dextran sodium sulfate; ef1 $\alpha$ : Eukaryotic translation elongation factor 1 alpha 1; ENS: Enteric nervous system; EPC: Epithelial cells; FZD9: Frizzled 9; IBS: Irritable bowel syndrome; IL: Interleukin; PE: phycoerythrin; Sox2: SRY-Box transcription factor 2; TNF: Tumor necrosis factor; WNT: Wingless-related integration site; 5-HT: Serotonin. 


\section{References}

1. Drossman, D.A. Functional Gastrointestinal Disorders: History, Pathophysiology, Clinical Features and Rome IV. Gastroenterology 2016, 150, 1262-1279.e2. [CrossRef]

2. Enck, P.; Aziz, Q.; Barbara, G.; Farmer, A.D.; Fukudo, S.; Mayer, E.A.; Niesler, B.; Quigley, E.M.; Rajilić-Stojanović, M.; Schemann, M.; et al. Irritable bowel syndrome. Nat. Rev. Dis. Primers 2016, 2, 16014. [CrossRef]

3. Schmulson, M.J.; Drossman, D.A. What Is New in Rome IV. J. Neurogastroenterol. Motil. 2017, 23, 151-163. [CrossRef]

4. Lacy, B.E.; Chey, W.D.; Lembo, A.J. New and Emerging Treatment Options for Irritable Bowel Syndrome. Gastroenterol. Hepatol. 2015, 11, 1-19.

5. Lembo, A.J.; Lacy, B.E.; Zuckerman, M.J.; Schey, R.; Dove, L.S.; Andrae, D.A.; Davenport, J.M.; McIntyre, G.; Lopez, R.; Turner, L.; et al. Eluxadoline for Irritable Bowel Syndrome with Diarrhea. N. Engl. J. Med. 2016, 374, 242-253. [CrossRef]

6. Chadwick, V.S.; Chen, W.; Shu, D.; Paulus, B.; Bethwaite, P.; Tie, A.; Wilson, I. Activation of the mucosal immune system in irritable bowel syndrome. Gastroenterology 2002, 122, 1778-1783. [CrossRef]

7. Stasi, C.; Rosselli, M.; Bellini, M.; Laffi, G.; Milani, S. Altered neuro-endocrine-immune pathways in the irritable bowel syndrome: The top-down and the bottom-up model. J. Gastroenterol. 2012, 47, 1177-1185. [CrossRef]

8. Hughes, P.A.; Harrington, A.M.; Castro, J.; Liebregts, T.; Adam, B.; Grasby, D.J.; Isaacs, N.J.; Maldeniya, L.; Martin, C.M.; Persson, J.; et al. Sensory neuro-immune interactions differ between irritable bowel syndrome subtypes. Gut 2013, 62, $1456-1465$. [CrossRef]

9. Hughes, K.R.; Sablitzky, F.; Mahida, Y.R. Expression profiling of Wnt family of genes in normal and inflammatory bowel disease primary human intestinal myofibroblasts and normal human colonic crypt epithelial cells. Inflamm. Bowel Dis. 2011, 17, 213-220. [CrossRef]

10. Ford, A.C.; Moayyedi, P.; Lacy, B.E.; Lembo, A.J.; Saito, Y.A.; Schiller, L.R.; Soffer, E.E.; Spiegel, B.M.; Quigley, E.M.; The Task Force on the Management of Functional Bowel Disorders. American College of Gastroenterology monograph on the management of irritable bowel syndrome and chronic idiopathic constipation. Am. J. Gastroenterol. 2014, 109 (Suppl. 1), S2-S26. [CrossRef]

11. Chey, W.D.; Kurlander, J.; Eswaran, S. Irritable bowel syndrome: A clinical review. JAMA 2015, 313, 949-958. [CrossRef]

12. Liu, J.P.; Yang, M.; Liu, Y.X.; Wei, M.; Grimsgaard, S. Herbal medicines for treatment of irritable bowel syndrome. Cochrane Database Syst. Rev. 2006, CD004116. [CrossRef]

13. Holtmann, G.; Schrenk, D.; Madisch, A.; Allescher, H.D.; Ulrich-Merzenich, G.; Mearin, F.; Larrey, D.; Malfertheiner, P. Use of Evidence-Based Herbal Medicines for Patients with Functional Gastrointestinal Disorders: A Conceptional Framework for Risk-Benefit Assessment and Regulatory Approaches. Dig. Dis. 2020, 38, 269-279. [CrossRef]

14. Rösch, W.; Vinson, B.; Sassin, I. A randomised clinical trial comparing the efficacy of a herbal preparation STW 5 with the prokinetic drug cisapride in patients with dysmotility type of functional dyspepsia. Z. Gastroenterol. 2002, 40, 401-408. [CrossRef]

15. Madisch, A.; Holtmann, G.; Mayr, G.; Vinson, B.; Hotz, J. Treatment of functional dyspepsia with a herbal preparation. A double-blind, randomized, placebo-controlled, multicenter trial. Digestion 2004, 69, 45-52. [CrossRef]

16. Madisch, A.; Holtmann, G.; Plein, K.; Hotz, J. Treatment of irritable bowel syndrome with herbal preparations: Results of a double-blind, randomized, placebo-controlled, multi-centre trial. Aliment. Pharmacol. Ther. 2004, 19, 271-279. [CrossRef]

17. Raedsch, R.; Hanisch, J.; Bock, P.; Sibaev, A.; Vinson, B.; Gundermann, K.J. Assessment of the efficacy and safety of the phytopharmacon STW 5 versus metoclopramide in functional dyspepsia-A retrolective cohort study. Z. Gastroenterol. 2007, 45, 1041-1048. [CrossRef]

18. von Arnim, U.; Peitz, U.; Vinson, B.; Gundermann, K.J.; Malfertheiner, P. STW 5, a phytopharmacon for patients with functional dyspepsia: Results of a multicenter, placebo-controlled double-blind study. Am. J. Gastroenterol. 2007, 102, 1268-1275. [CrossRef]

19. Braden, B.; Caspary, W.; Börner, N.; Vinson, B.; Schneider, A.R. Clinical effects of STW 5 (Iberogast) are not based on acceleration of gastric emptying in patients with functional dyspepsia and gastroparesis. Neurogastroenterol. Motil. 2009, 21, 632-638. [CrossRef]

20. Abdel-Aziz, H.; Kelber, O.; Lorkowski, G.; Storr, M. Evaluating the Multitarget Effects of Combinations through Multistep Clustering of Pharmacological Data: The Example of the Commercial Preparation Iberogast. Planta Med. 2017, 83, 1130-1140. [CrossRef]

21. Allescher, H.D.; Abdel-Aziz, H. Mechanism of Action of STW 5 in Functional Dyspepsia and IBS: The Origin of Multi-Target. Dig. Dis. 2017, 35 (Suppl. 1), 18-24. [CrossRef]

22. Allescher, H.D.; Wagner, H. STW 5/Iberogast: Multi-target-action for treatment of functional dyspepsia and irritable bowel syndrome. Wien. Med. Wochenschr. 2007, 157, 301-307. [CrossRef]

23. Ottillinger, B.; Storr, M.; Malfertheiner, P.; Allescher, H.D. STW 5 (lberogast ${ }^{\circledR}$ )-a safe and effective standard in the treatment of functional gastrointestinal disorders. Wien. Med. Wochenschr. 2013, 163, 65-72. [CrossRef]

24. Malfertheiner, P. STW 5 (Iberogast) Therapy in Gastrointestinal Functional Disorders. Dig. Dis. 2017, 35 (Suppl. 1), 25-29. [CrossRef]

25. Di Liddo, R.; Bertalot, T.; Schuster, A.; Schrenk, S.; Tasso, A.; Zanusso, I.; Conconi, M.T.; Schäfer, K.H. Anti-inflammatory activity of Wnt signaling in enteric nervous system: In vitro preliminary evidences in rat primary cultures. J. Neuroinflamm. 2015, 12, 23. [CrossRef]

26. Le Guen, L.; Marchal, S.; Faure, S.; de Santa Barbara, P. Mesenchymal-epithelial interactions during digestive tract development and epithelial stem cell regeneration. Cell Mol. Life Sci. 2015, 72, 3883-3896. [CrossRef]

27. Simonetti, M.; Agarwal, N.; Stösser, S.; Bali, K.K.; Karaulanov, E.; Kamble, R.; Pospisilova, B.; Kurejova, M.; Birchmeier, W.; Niehrs, C.; et al. Wnt-Fzd signaling sensitizes peripheral sensory neurons via distinct noncanonical pathways. Neuron 2014, 83, 104-121. [CrossRef]

28. Katoh, M. WNT signaling in stem cell biology and regenerative medicine. Curr. Drug Targets 2008, 9, 565-570. [CrossRef] 
29. Ratanasirintrawoot, S.; Israsena, N. Stem Cells in the Intestine: Possible Roles in Pathogenesis of Irritable Bowel Syndrome. J. Neurogastroenterol. Motil. 2016, 22, 367-382. [CrossRef]

30. Neumann, J.; Schaale, K.; Farhat, K.; Endermann, T.; Ulmer, A.J.; Ehlers, S.; Reiling, N. Frizzled1 is a marker of inflammatory macrophages, and its ligand Wnt3a is involved in reprogramming Mycobacterium tuberculosis-infected macrophages. FASEB J. 2010, 24, 4599-4612. [CrossRef]

31. Ma, B.; Hottiger, M.O. Crosstalk between Wnt/ $\beta$-Catenin and NF-kB Signaling Pathway during Inflammation. Front. Immunol. 2016, 7, 378. [CrossRef]

32. Manicassamy, S.; Reizis, B.; Ravindran, R.; Nakaya, H.; Salazar-Gonzalez, R.M.; Wang, Y.C.; Pulendran, B. Activation of beta-catenin in dendritic cells regulates immunity versus tolerance in the intestine. Science 2010, 329, 849-853. [CrossRef]

33. Di Liddo, R.; Bertalot, T.; Schuster, A.; Schrenk, S.; Müller, O.; Apfel, J.; Reischmann, P.; Rajendran, S.; Sfriso, R.; Gasparella, M.; et al. Fluorescence-based gene reporter plasmid to track canonical Wnt signaling in ENS inflammation. Am. J. Physiol. Gastrointest. Liver Physiol. 2016, 310, G337-G346. [CrossRef]

34. Sen, M.; Ghosh, G. Transcriptional outcome of Wnt-Frizzled signal transduction in inflammation: Evolving concepts. J. Immunol. 2008, 181, 4441-4445. [CrossRef]

35. Jridi, I.; Canté-Barrett, K.; Pike-Overzet, K.; Staal, F.J.T. Inflammation and Wnt Signaling: Target for Immunomodulatory Therapy? Front. Cell Dev. Biol. 2020, 8, 615131. [CrossRef]

36. Yang, Y.; Tomkovich, S.; Jobin, C. Could a swimming creature inform us on intestinal diseases? Lessons from zebrafish. Inflamm. Bowel Dis. 2014, 20, 956-966. [CrossRef]

37. Scanzi, J.; Accarie, A.; Muller, E.; Pereira, B.; Aissouni, Y.; Goutte, M.; Joubert-Zakeyh, J.; Picard, E.; Boudieu, L.; Mallet, C.; et al. Colonic overexpression of the T-type calcium channel Ca. Neurogastroenterol. Motil. 2016, 28, 1632-1640. [CrossRef]

38. Camilleri, M.; Carlson, P.; Valentin, N.; Acosta, A.; O’Neill, J.; Eckert, D.; Dyer, R.; Na, J.; Klee, E.W.; Murray, J.A. Pilot study of small bowel mucosal gene expression in patients with irritable bowel syndrome with diarrhea. Am. J. Physiol. Gastrointest. Liver Physiol. 2016, 311, G365-G376. [CrossRef]

39. D’Antongiovanni, V.; Pellegrini, C.; Fornai, M.; Colucci, R.; Blandizzi, C.; Antonioli, L.; Bernardini, N. Intestinal epithelial barrier and neuromuscular compartment in health and disease. World J. Gastroenterol. 2020, 26, 1564-1579. [CrossRef]

40. You, J.; Nguyen, A.V.; Albers, C.G.; Lin, F.; Holcombe, R.F. Wnt pathway-related gene expression in inflammatory bowel disease. Dig. Dis. Sci. 2008, 53, 1013-1019. [CrossRef]

41. Kim, Y.S.; Ho, S.B. Intestinal goblet cells and mucins in health and disease: Recent insights and progress. Curr. Gastroenterol. Rep. 2010, 12, 319-330. [CrossRef]

42. Dharmani, P.; Leung, P.; Chadee, K. Tumor necrosis factor- $\alpha$ and Muc2 mucin play major roles in disease onset and progression in dextran sodium sulphate-induced colitis. PLoS ONE 2011, 6, e25058. [CrossRef]

43. Cheng, P.; Yao, J.; Wang, C.; Zhang, L.; Kong, W. Molecular and cellular mechanisms of tight junction dysfunction in the irritable bowel syndrome. Mol. Med. Rep. 2015, 12, 3257-3264. [CrossRef]

44. Wallace, K.N.; Akhter, S.; Smith, E.M.; Lorent, K.; Pack, M. Intestinal growth and differentiation in zebrafish. Mech. Dev. 2005, 122, 157-173. [CrossRef] [PubMed]

45. Graham, V.; Khudyakov, J.; Ellis, P.; Pevny, L. SOX2 functions to maintain neural progenitor identity. Neuron 2003, 39, 749-765. [CrossRef]

46. Heanue, T.A.; Pachnis, V. Prospective identification and isolation of enteric nervous system progenitors using Sox2. Stem Cells 2011, 29, 128-140. [CrossRef] [PubMed]

47. Laranjeira, C.; Sandgren, K.; Kessaris, N.; Richardson, W.; Potocnik, A.; Vanden Berghe, P.; Pachnis, V. Glial cells in the mouse enteric nervous system can undergo neurogenesis in response to injury. J. Clin. Investig. 2011, 121, 3412-3424. [CrossRef] [PubMed]

48. Colomier, E.; Algera, J.; Melchior, C. Pharmacological Therapies and Their Clinical Targets in Irritable Bowel Syndrome With Diarrhea. Front. Pharmacol. 2020, 11, 629026. [CrossRef]

49. Ohman, L.; Simrén, M. Pathogenesis of IBS: Role of inflammation, immunity and neuroimmune interactions. Nat. Rev. Gastroenterol. Hepatol. 2010, 7, 163-173. [CrossRef]

50. Abdul Rani, R.; Raja Ali, R.A.; Lee, Y.Y. Irritable bowel syndrome and inflammatory bowel disease overlap syndrome: Pieces of the puzzle are falling into place. Intest. Res. 2016, 14, 297-304. [CrossRef] [PubMed]

51. Goldsmith, J.R.; Jobin, C. Think small: Zebrafish as a model system of human pathology. J. Biomed. Biotechnol. 2012, 2012, 817341. [CrossRef]

52. Chassaing, B.; Srinivasan, G.; Delgado, M.A.; Young, A.N.; Gewirtz, A.T.; Vijay-Kumar, M. Fecal lipocalin 2, a sensitive and broadly dynamic non-invasive biomarker for intestinal inflammation. PLoS ONE 2012, 7, e44328. [CrossRef]

53. Spiller, R.; Garsed, K. Infection, inflammation, and the irritable bowel syndrome. Dig. Liver Dis. 2009, 41, 844-849. [CrossRef]

54. Buhner, S.; Li, Q.; Vignali, S.; Barbara, G.; De Giorgio, R.; Stanghellini, V.; Cremon, C.; Zeller, F.; Langer, R.; Daniel, H.; et al. Activation of human enteric neurons by supernatants of colonic biopsy specimens from patients with irritable bowel syndrome. Gastroenterology 2009, 137, 1425-1434. [CrossRef]

55. Clarke, G.; Quigley, E.M.; Cryan, J.F.; Dinan, T.G. Irritable bowel syndrome: Towards biomarker identification. Trends Mol. Med. 2009, 15, 478-489. [CrossRef] 
56. Dinan, T.G.; Quigley, E.M.; Ahmed, S.M.; Scully, P.; O’Brien, S.; O’Mahony, L.; O’Mahony, S.; Shanahan, F.; Keeling, P.W. Hypothalamic-pituitary-gut axis dysregulation in irritable bowel syndrome: Plasma cytokines as a potential biomarker? Gastroenterology 2006, 130, 304-311. [CrossRef]

57. Liebregts, T.; Adam, B.; Bredack, C.; Röth, A.; Heinzel, S.; Lester, S.; Downie-Doyle, S.; Smith, E.; Drew, P.; Talley, N.J.; et al. Immune activation in patients with irritable bowel syndrome. Gastroenterology 2007, 132, 913-920. [CrossRef]

58. Patel, S.R.; Singh, A.; Misra, V.; Misra, S.P.; Dwivedi, M.; Trivedi, P. Levels of interleukins 2, 6, 8, and 10 in patients with irritable bowel syndrome. Indian J. Pathol. Microbiol. 2017, 60, 385-389. [CrossRef]

59. Dinan, T.G.; Clarke, G.; Quigley, E.M.; Scott, L.V.; Shanahan, F.; Cryan, J.; Cooney, J.; Keeling, P.W. Enhanced cholinergic-mediated increase in the pro-inflammatory cytokine IL-6 in irritable bowel syndrome: Role of muscarinic receptors. Am. J. Gastroenterol. 2008, 103, 2570-2576. [CrossRef]

60. Xia, Y.; Hu, H.Z.; Liu, S.; Ren, J.; Zafirov, D.H.; Wood, J.D. IL-1beta and IL-6 excite neurons and suppress nicotinic and noradrenergic neurotransmission in guinea pig enteric nervous system. J. Clin. Investig. 1999, 103, 1309-1316. [CrossRef]

61. O'Malley, D.; Quigley, E.M.; Dinan, T.G.; Cryan, J.F. Do interactions between stress and immune responses lead to symptom exacerbations in irritable bowel syndrome? Brain Behav. Immun. 2011, 25, 1333-1341. [CrossRef]

62. Natale, L.; Piepoli, A.L.; De Salvia, M.A.; De Salvatore, G.; Mitolo, C.I.; Marzullo, A.; Portincasa, P.; Moschetta, A.; Palasciano, G.; Mitolo-Chieppa, D. Interleukins 1 beta and 6 induce functional alteration of rat colonic motility: An in vitro study. Eur. J. Clin. Investig. 2003, 33, 704-712. [CrossRef]

63. Kindt, S.; Vanden Berghe, P.; Boesmans, W.; Roosen, L.; Tack, J. Prolonged IL-1beta exposure alters neurotransmitter and electrically induced $\mathrm{Ca}(2+)$ responses in the myenteric plexus. Neurogastroenterol. Motil. 2010, 22, 321-e385. [CrossRef]

64. McKernan, D.P.; Gaszner, G.; Quigley, E.M.; Cryan, J.F.; Dinan, T.G. Altered peripheral toll-like receptor responses in the irritable bowel syndrome. Aliment. Pharmacol. Ther. 2011, 33, 1045-1052. [CrossRef]

65. Buckley, M.M.; O'Halloran, K.D.; Rae, M.G.; Dinan, T.G.; O'Malley, D. Modulation of enteric neurons by interleukin-6 and corticotropin-releasing factor contributes to visceral hypersensitivity and altered colonic motility in a rat model of irritable bowel syndrome. J. Physiol. 2014, 592, 5235-5250. [CrossRef]

66. Kyoko, O.O.; Kono, H.; Ishimaru, K.; Miyake, K.; Kubota, T.; Ogawa, H.; Okumura, K.; Shibata, S.; Nakao, A. Expressions of tight junction proteins Occludin and Claudin-1 are under the circadian control in the mouse large intestine: Implications in intestinal permeability and susceptibility to colitis. PLoS ONE 2014, 9, e98016. [CrossRef]

67. Allescher, H.D.; Burgell, R.; Malfertheiner, P.; Mearin, F. Multi-target Treatment for Irritable Bowel Syndrome with STW 5: Pharmacological Modes of Action. J. Gastrointestin. Liver Dis. 2020, 29, 227-233. [CrossRef]

68. Dhawan, P.; Singh, A.B.; Deane, N.G.; No, Y.; Shiou, S.R.; Schmidt, C.; Neff, J.; Washington, M.K.; Beauchamp, R.D. Claudin-1 regulates cellular transformation and metastatic behavior in colon cancer. J. Clin. Investig. 2005, 115, 1765-1776. [CrossRef]

69. Miwa, N.; Furuse, M.; Tsukita, S.; Niikawa, N.; Nakamura, Y.; Furukawa, Y. Involvement of claudin-1 in the beta-catenin/Tcf signaling pathway and its frequent upregulation in human colorectal cancers. Oncol. Res. 2001, 12, 469-476. [CrossRef]

70. O'Garra, A.; Vieira, P. T(H)1 cells control themselves by producing interleukin-10. Nat. Rev. Immunol. 2007, 7, 425-428. [CrossRef]

71. Krueger, D.; Gruber, L.; Buhner, S.; Zeller, F.; Langer, R.; Seidl, S.; Michel, K.; Schemann, M. The multi-herbal drug STW 5 (Iberogast) has prosecretory action in the human intestine. Neurogastroenterol. Motil. 2009, 21, 1203-e1110. [CrossRef]

72. Allam, S.; Krueger, D.; Demir, I.E.; Ceyhan, G.; Zeller, F.; Schemann, M. Extracts from peppermint leaves, lemon balm leaves and in particular angelica roots mimic the pro-secretory action of the herbal preparation STW 5 in the human intestine. Phytomedicine 2015, 22, 1063-1070. [CrossRef]

73. Aleström, P.; D’Angelo, L.; Midtlyng, P.J.; Schorderet, D.F.; Schulte-Merker, S.; Sohm, F.; Warner, S. Zebrafish: Housing and husbandry recommendations. Lab. Anim. 2020, 54, 213-224. [CrossRef]

74. Oehlers, S.H.; Flores, M.V.; Hall, C.J.; Okuda, K.S.; Sison, J.O.; Crosier, K.E.; Crosier, P.S. Chemically induced intestinal damage models in zebrafish larvae. Zebrafish 2013, 10, 184-193. [CrossRef]

75. Chira, A.; Dumitrascu, D.L. Serum biomarkers for irritable bowel syndrome. Clujul Med. 2015, 88, 258-264. [CrossRef]

76. Bertiaux-Vandaële, N.; Youmba, S.B.; Belmonte, L.; Lecleire, S.; Antonietti, M.; Gourcerol, G.; Leroi, A.M.; Déchelotte, P.; Ménard, J.F.; Ducrotté, P.; et al. The expression and the cellular distribution of the tight junction proteins are altered in irritable bowel syndrome patients with differences according to the disease subtype. Am. J. Gastroenterol. 2011, 106, 2165-2173. [CrossRef]

77. Kumar, S.; Shukla, R.; Ranjan, P.; Kumar, A. Interleukin-10: A Compelling Therapeutic Target in Patients With Irritable Bowel Syndrome. Clin. Ther. 2017, 39, 632-643. [CrossRef]

78. Schäfer, K.H.; Saffrey, M.J.; Burnstock, G.; Mestres-Ventura, P. A new method for the isolation of myenteric plexus from the newborn rat gastrointestinal tract. Brain Res. Brain Res. Protoc. 1997, 1, 109-113. [CrossRef] 